\title{
O Impacto da Gestão do Clima Organizacional no Comportamento das Pessoas do Setor Público
}

\author{
Teilma Maria da Silva ${ }^{1}$; Cíntia Milena Cid Viana ${ }^{2}$; Leandro da Cruz Feitosa ${ }^{3}$
}

\begin{abstract}
Resumo: Uma mudança no modo de repensar a administração pública vem colocando as pessoas em um certo lugar de destaque. Nenhuma instituição consegue o sucesso se não mantiver os seus colaboradores satisfeitos com o seu trabalho. Cada vez mais o serviço público vêm se preocupando com o bem-estar das pessoas. Questões mais humanas tem sido consideradas um grande diferencial das empresas, quando se trata de vencer a competitividade. Hoje, para que se alcance bons resultados, há que primeiro oferecer algo mais do que simplesmente uma remuneração atraente, para conquistar maior compromisso dos colaboradores. É preciso investir em condições laborais que sinalizem melhoria na qualidade de vida dos funcionários, seu aperfeiçoamento profissional e um ambiente livre de riscos. Por isso a importância da avaliação do Clima Organizacional e o impacto que ele tem sobre o comportamento das pessoas. O presente artigo propõe, enquanto objetivo geral, discutir se o comportamento das pessoas, bem como seu desempenho, estão significativamente associados ao clima organizacional. A metodologia utilizada foi a revisão bibliográfica acerca da importância do clima organizacional para organizações.
\end{abstract}

Palavras Chave: Clima Organizacional. Fator Humano. Satisfação no Trabalho.

\section{Organizational Climate Management Impact in the Behavior of the Public Sector People}

\begin{abstract}
A change in the way of rethinking public administration has put people in a certain place of prominence. No institution can succeed if it does not keep its employees satisfied with their work. Increasingly the public service has been worrying about the well-being of people. More humane issues have been considered as a major differential for companies when it comes to overcoming competitiveness. Today, in order to achieve good results, we must first offer something more than simply attractive remuneration, in order to achieve greater commitment from our employees. It is necessary to invest in working conditions that signal improvement in the quality of life of employees, their professional improvement and a risk-free environment. Therefore the importance of the evaluation of the Organizational Climate and the impact that it has on the behavior of the people. The present article proposes, as a general objective, to discuss if the behavior of the people, as well as their performance, are significantly associated to the organizational climate. The methodology used was the bibliographic review about the importance of the organizational climate for organizations.
\end{abstract}

Keywords: Organizational Climate. Human Factor. Job Satisfaction.

\footnotetext{
${ }^{1}$ Especialista em Gestão de Pessoas com Ênfase em Gestão por Competência - UFBA. Pós-graduanda em Gestão Pública UNIVASF. Contato: teilma_fraga@hotmail.com;

${ }^{2}$ Pós graduação em finanças - FGV. Graduação em ciência contábeis _ UFRN. Graduação em Ciência Econômicas Faculdade Católica de Ciências Econômicas - Bahia; Pós-Graduanda em Gestão Pública - UNIVASF. Contato: cintiamilenacid@hotmail.com;

${ }^{3}$ Bacharel em Serviço Social - Anhanguera. Formação Pedagógica em História- UNOPAR. Especialista em Gestão Social, Políticas Públicas e Rede de Defesa de Direitos- UNOPAR. Especialista em Gestão Pública Municipal - UFBA (Orientador).
} 


\section{Introdução}

Este artigo aborda a gestão do clima organizacional como ferramenta importante na administração do comportamento das pessoas, visando um plano de desenvolvimento para melhor gerir as pessoas e a organização para o alcance das metas institucionais nos setores da administração pública do estado da Bahia. São apontados tópicos relevantes para os administradores públicos, servidores públicos no papel de líderes; coordenadores e estudantes de diversas especialidades na área de administração, psicologia, e àqueles que possam apresentar interesse pelo o assunto. É apresentada uma reflexão sobre a influência do clima organizacional no comportamento humano e alguns critérios para se conseguir a satisfação dos colaboradores e construir um clima organizacional favorável para o alcance das metas institucionais.

A influência do clima organizacional nas instituições pública e nos servidores, objetiva verificar como os setores públicos podem atuar para conseguir a satisfação dos servidores no sentido da excelência nos serviços públicos. As pessoas constituem o principal ativo da organização. Por isso a necessidade de tornar as organizações públicas mais conscientes e atentas a seus funcionários. Assim, faz-se necessário responder o seguinte questionamento: qual o impacto da gestão do clima organizacional no comportamento das pessoas da esfera pública?

A gestão do clima organizacional contribui significativamente no comportamento das pessoas, e falta aos gestores maior conhecimento sobre esse aspecto. Nesse sentido, visando amenizar possíveis tendências no setor público, este artigo apresenta sugestões no sentido de melhorar o clima organizacional e, por conseguinte o comportamento humano.

O objetivo geral é discutir se o comportamento das pessoas e o seu desempenho estão significativamente associados ao clima organizacional; os objetivos específicos são: identificar as principais influências decorrentes do clima sobre as pessoas e apontar soluções para o andamento dos processos e o alcance da excelência profissional nos setores públicos. 


\title{
Abordagem conceitual sobre Clima Organizacional
}

Com a finalidade de adentrarmos mais a fundo e de tornar mais clara a abordagem do tema em questão, torna-se importante a definição de "clima organizacional".

De acordo com Chiavenato (1999):

O clima organizacional reflete o modo como as pessoas interagem umas com as outras, com os clientes e fornecedores internos e externos, bem como o grau de satisfação com o contexto que as cerca. O clima organizacional pode ser agradável, receptivo, caloroso e envolvente, em um extremo, ou desagradável, agressivo, frio e alienante em outro extremo (CHIAVENATO, 1999, p. 440).

Segundo Oliveira (1995):

\begin{abstract}
Clima interno é o estado em que se encontra a empresa ou parte dela em dado momento, estado momentâneo e passível de alteração mesmo em curto espaço de tempo em razão de novas influências surgidas, e que decorre das decisões e ações pretendidas pela empresa, postas em prática ou não, e/ou das reações dos empregados a essas ações ou à perspectiva delas. Esse estado interno pode ter sido influenciado por acontecimentos externos e/ou internos à empresa e pode ser origem de desdobramentos em novos acontecimentos, decisões e ações internas (OLIVEIRA, 1995, p.47).
\end{abstract}

O clima não é único em toda e qualquer organização. Por isso, o mais importante é estar sempre envolvido em criar o próprio clima organizacional no cotidiano laboral, ou seja, atuando como agentes promotores do bem-estar organizacional para assim, conseguir a tão sonhada excelência nos serviços prestados pela a esfera pública.

\section{Comportamento Organizacional e a sua importância}

Devido às inúmeras mudanças nos últimos anos, cada vez mais se faz necessário que as organizações e profissionais repensem e se preocupem com o comportamento organizacional. Para tanto, é primordial refletir o que vem a ser comportamento organizacional. Assim, comportamento organizacional é o estudo de indivíduos e grupos em organizações. Ou seja, é 
o estudo do comportamento das pessoas e grupos em situação de trabalho, bem como seus impactos no ambiente organizacional.

$\mathrm{O}$ estudo dos comportamentos parece estar relacionado a fatores que exercem grande influência nos resultados finais alcançados pela instituição como: estruturas hierárquicas, formas de liderança, processos grupais, aprendizagem, percepção, atitudes, formas de adaptação às mudanças, gerenciamento de conflitos internos, dimensionamento do trabalho, entre outros que tendem a afetar os indivíduos e as equipes organizacionais.

As organizações públicas têm uma importante tarefa neste contexto. Devido ao seu perfil, aparelhamento do Estado, para a prestação dos serviços públicos, para a gestão dos bens públicos e dos interesses da comunidade, onde seus servidores, geralmente possuem estabilidade. É importante trabalhar o clima e o comportamento das pessoas com a finalidade de se obter a boa convivência, motivação e o alcance das metas institucionais. "As condições ambientais, no entanto, não são suficientes para induzir o estado de motivação para o trabalho. Para que haja motivação, de acordo com Herzberg, é preciso que a pessoa esteja sintonizada com seu trabalho, que enxergue nele a possibilidade de exercitar suas habilidades ou desenvolver suas aptidões." (MAXIMIANO, 2007 p.268-269).

Sabe-se que "ambiente" é o conceito indicativo da relação de contingência entre o comportamento humano e as consequências do comportamento (o que implica em uma ação modificadora tanto do ambiente quanto do comportamento). Ou seja, o ser humano responde ao ambiente se comportando e é também modificado pela interação deste meio. Cada organização tem suas crenças, seus valores e princípios-guia que formam sua cultura organizacional própria. Esta cultura é percebida a partir do comportamento das pessoas quando adentram a organização. A tarefa das empresas, ante tal realidade, normalmente partindo-se do setor de RH ou Gestão de Pessoal, é tentar alinhar o mais próximo possível, o comportamento dos novos colaboradores à uma conduta esperada pela organização, em conformidade com sua cultura organizacional.

Para Morgan (2000 p.82),

Quando se fala sobre cultura, "geralmente refere-se ao padrão de desenvolvimento refletido no sistema de conhecimento, ideologia, valores, leis e rituais diários de uma sociedade". Assim, cultura significa que diferentes grupos de pessoas têm diferentes modos de vida e uma organização também tem uma cultura a qual poderia ser identificada com a sua personalidade. Por fim, cultura organizacional é um sistema de valores compartilhados dentro de uma organização que determina, posteriormente e 
em grande parte, a forma como esta organização deve agir (sejam os empregados, os sócios, a administração, os colaboradores, etc.).

\section{Gestão de Recursos Humanos e o viés do Comportamento Organizacional}

Inúmeras situações dentro de uma organização tornam-se uma indicação de que algo não vai bem. Em outras palavras, oferecem informações sobre como anda o ambiente organizacional ou, como está o clima. Neste caso, quando indicadores de um clima organizacional apontam insatisfatórios, deve-se observar mais amiúde quais são, ou a que condições pode estar relacionados. Se às condições físicas de trabalho estão sendo percebidas como inadequadas; como a empresa está em termos de benefícios, se estes atendem às demandas básicas dos servidores; se estão relacionadas ao modo como os chefes administram suas áreas, ou como estes se relacionam com seus subordinados. Podem estar associado a alguma restrição na participação dos servidores em decisões da instituição, ou à alguma impossibilidade de realizar internamente numa carreira profissional mais promissora, por exemplo. Por outro lado, pode haver indicativos que indiquem a existência de um clima organizacional favorável. Nestes casos, normalmente há uma participação mais espontânea dos colaboradores naquelas atividades consideradas extras; maior senso poupança e de economia; melhor relacionamento e envolvimento dos colaboradores nas tarefas conjuntas; melhora a qualidade dos produtos e serviços oferecidos; e finalmente, há uma diminuição nas reclamações de clientes.

Analisando os estudos desenvolvidos na área de Gestão de Pessoas, observa-se a importância das pesquisas sobre o comportamento humano no ambiente institucional. Tal fato leva a abordar, no presente artigo, algumas contribuições válidas, tais como a identificação de possíveis desvios de conduta que tendem a levar a um comprometimento dos objetivos a serem alcançados pelas organizações. Diante de tal reflexão, torna-se necessária a abordagem da Psicologia Organizacional para refletir bons resultados na gestão das pessoas. "Diferentemente da tecnologia, das finanças e da comercialização, a administração das empresas tem deixado claro que o elemento humano se caracteriza como fator de inquestionável importância com relação ao comprometimento de se chegar aos objetivos organizacionais pretendidos." (BERGAMINI, 2011, p. 12) 
Destarte, a Psicologia aplicada às inúmeras circunstâncias organizacionais, conforme Bergamini (2011), auxilia bastante no desenvolvimento de pesquisas acerca da motivação para o trabalho, da moral e do clima organizacional via observações diretas, das características de líderes eficazes, através da aplicação de entrevistas e questionários. Haja vista que só $o$ gerenciamento forte centrado em pessoas de liderança holística e a forças adjuntas, são capazes de energizar e motivar este processo adequadamente. Uma organização pode fabricar diversos produtos diferentes ou todas idênticas, que podem ser utilizados na indústria, ativos ou bens fabricados em série. Mas pessoas são diferentes umas das outras, nunca foram máquinas. Possuem experiências, valores, criatividade, emoção, motivação, expectativas e cultura precedidas de grandes diferenças. Pertencem a grupos de convívio social diferentes. Vivem de percepções, diferentes. Possuem níveis de inteligência e formação escolar diferentes. Gerentes e líderes holísticos têm mesmo de se utilizarem da habilidade humana, pedagógica-coaching, para saberem detectar as necessidades de educação, treinamento, harmonia das pessoas e do grupo e conduzirem o ativo pensante o "capital humano". As pessoas trazem as soluções, resultados e a produtividade.

\section{Porque e para que se pesquisar o clima organizacional?}

Porque a problematizarão: alcance de objetivos e motivação para o trabalho - tem o resultado ponderado de um bom clima organizacional. A pesquisas do clima interno torna possível diagnosticar problemas que possam está afetando o andamento dos serviços. Segundo Kahale (2003, p. 2), "esta atitude da empresa, de fazer a pesquisa de clima, eleva bastante o índice de motivação dos funcionários. Eles sentem-se participando, sentem-se ouvidos e respeitados em suas opiniões. A crença na empresa se eleva sensivelmente".

No entanto, para que os trabalhadores possam geral algum resultado ou mudança concreta, uma pesquisa de clima deve ser levada a cabo, e maneira organizada, séria e comprometida, compartilhando-se os resultados com todos os colaboradores que participarem. Quando não compartilhados, os de iniciativas como essa, tende a ter efeito inverso: Gera descrença na empresa, podendo aumentar a sensação de insegurança e a relação dos colaboradores com a empresa passa a ser de grande desconfiança. 
De acordo com Kahale (2003):

Um clima organizacional bem trabalhado pode trazer alguns benefícios para a organização: retenção de talentos; diminuição do índice de doenças psicossomáticas; treinamentos sintonizados com os objetivos da empresa, aumento no comprometimento dos funcionários com a empresa (sentem-se responsáveis por ela, como coautores); credibilidade; integração; união; adequação do processo de seleção/premiação, entre outros (KAHALE, 2003, p. 25)

\section{Ferramentas que podem auxiliar os Gestores Público na condução de um bom Clima Organizacional}

$\mathrm{Na}$ administração pública é preciso que os gestores públicos compreendam a importância de conhecer as diversas ferramentas de gestão pública que podem ser utilizadas para auxiliarem na construção de um bom ambiente de trabalho e assim, transformar hábitos e permitir que os seus colaboradores vivenciem experiencias cada vez melhores dentro da organização. Essa transformação precisa ser entendida como um processo global, sem volta, e cada vez mais presente e continuo. As organizações públicas que tem caminhado para uma orientação mais gerencial e menos burocrática, objetivando cumprir os princípios da eficiência e da eficácia, tem adotado ferramentas de gestão, que antes eram utilizadas somente em instituições privadas.

\section{Endomarketing na esfera pública como ferramenta de satisfação dos servidores}

O Endomarketing geralmente é utilizado quando se busca a satisfação dos empregados, que passam a ser tratados como clientes internos. Imagina-se que empregados satisfeitos geram resultados e ganhos, em termos de qualidade e produtividade para a organização, além da satisfação aos clientes. O endomarketing apresenta como característica principal a comunicação interna. Dessa forma, fortalece o relacionamento organizacional. É possível que, programas assim só tenham sucesso com o apoio da alta administração.

Para Robbins (2002, p.135) fatores que determinam a satisfação do empregado são: 
a) trabalhos que lhes dêem oportunidades de crescimento e de que seja oferecido retorno quão bem eles estão se saindo; b) recompensas justas, de acordo com a legislação vigente, exigências de trabalho, habilidade do empregado. O resultado mais provável é a satisfação; c) boas condições de trabalho, para conforto pessoal e realização das atividades e; d) apoio dos colegas pois o retorno financeiro é interesse de todo trabalhador mas a necessidade da integração social e reconhecimento por parte da organização também é um fato importante.

Neste sentido, torna-se muito crucial a comunicação entre a alta administração, coordenadores e demais trabalhadores, que assume cada vez mais, uma intensidade maior, quase que obrigando as organizações públicas a gerarem e repassarem informações, com maior velocidade e assertividade, aos diversos públicos a que atendem, sejam internos ou externos.

\section{A influência do endomarketing no comportamento e no clima organizacional}

Dispor de colaboradores bem engajados dentro da estrutura do serviço público, bem como também bem informados é sem dúvida um dos sonhos d de todas as esferas de governo. Na Administração Pública Brasileira, seguindo a tendência internacional, existem vários movimentos no sentido de modernizar e profissionalizar o serviço público tornando a gestão de pessoas uma ferramenta estratégica, especialmente nos períodos reformistas. É possível citar como exemplo o Decreto $n^{\circ}$ 5.707/2006 que instituiu a Política Nacional de Desenvolvimento de Pessoal (PNDP), cuja premissa teórica de fundo parece ser a gestão por competência atrelada à capacitação.

É nesse cenário que o endomarketing surge para complementar o tão sonhado clima organizacional, por ter influência direta com o comportamento das pessoas. Sabendo que as organizações comportam aglomerações humanas, com interesses comuns e também algum interesse divergente, eis que esta complexidade, de certa forma ambígua, é um desafio aos administradores públicos, que direcionam o Endomarketing, para a obtenção de resultados. A opinião do público interno normalmente exerce grande influência nas opiniões e perspectivas do público externo, inclusive do consumidor.

O Endomarketing existe para atrair e reter o primeiro cliente, ou seja, o cliente interno. Afinal, funcionários insatisfeitos com as condições de trabalho e com os próprios produtos lançados, irão fazer uma propaganda contraria cada vez que multiplicam fora da empresa à sensação de descontentamento que os dominam. E, caso estejam 
satisfeitos com a organização, a tendência é um marketing positivo para o cliente externo (ANDRADE, 2011, p.302).

Dentre as principais mudanças no clima organizacional obtidas quando se utiliza o endomarketing é uma liderança mais democrática, passando a dividir mais as responsabilidades, delegando poderes e, envolvendo-se com o desempenho e desenvolvimento da equipe. A comunicação interna tende a melhorar, tornando mais enriquecedoras as trocas e compartilhamentos de experiências, conhecimentos e opiniões; A cultura organizacional parece tornar-se mais descentralizada; O clima organizacional observa-se mais respeitoso, gerando maior confiança, cooperação e harmonia. A maior contribuição do endomarketing talvez esteja relacionada a uma melhoria no ambiente interno da organização. Um clima mais favorável, motivador e confiante se instala.

É absolutamente importante não se confundir o Endomarketing com a Comunicação Interna. Enquanto o primeiro tem a finalidade de melhorar a moral e a motivação dos colaboradores; a Comunicação interna faz funcionar uma interligação entre os setores da organização. Os dois são complementares entre si. Isto é, sem uma comunicação eficiente entre os setores, é provável que os colaboradores não fiquem bem informados e acabem passando dados incorretos ou incompletos para outros setores ou até mesmo para clientes, o que acabará gerando confusões internas ou insatisfação do consumidor, causando assim a desmotivação dos colaboradores. Por isso é importante alinhar a estratégia de comunicação interna e de endomarketing para que tudo aconteça conforme o planejado.

\section{Feedback}

O feedback é uma ferramenta indispensável para toda e qualquer organização. Por isso a sua importância no cotidiano dos gestores públicos. Essa ferramenta refere-se à avaliação que é dada a um grupo ou a algum colaborador individualmente, sobre as suas ações, qualidade da produção ou resultados. Embora seja considerado essencial para o bom funcionamento de uma instituição, existem muitos colaboradores e líderes que ainda não se utilizam corretamente desse instrumento de comunicação. É possível que a maioria dos gestores acredite que o feedback seja uma via de mão única: sendo assim, eles analisam e devolvem aos seus funcionários uma 
avaliação, cheia de críticas e recomendações. Na realidade, o feedback constitui-se numa via de mão dupla. Quem dá, também deve receber o retorno sobre seu procedimento enquanto colaborador. Para que as organizações cresçam e funcionem de modo ótimo e eficiente, é imprescindível que aqueles que estão em cargos de chefia estejam preparados receberem críticas e sugestões quato ao seu comportamento e atitudes na empresa, bem como novas ideias de seus funcionários.

De acordo com GODINHO, MENDES e BARREIROS (1995, p. 217) feedback:

"é a expressão genérica que identifica o mecanismo de retroalimentação
de qualquer sistema processador de informação". É o retorno de
informação que permite ao sistema avaliar o quanto foi cumprido os
objetivos, é uma condição obrigatória para ocorrer aprendizagem.

Existem 2 tipos de Feedbacks: O Positivo e Negativo. O Feedback Positivo é quando a equipe ou o colaborador alcançam as metas esperadas. Dar este feedback ao colaborador é bastante importante para que ele, ou a equipe saibam que estão no caminho certo em seus comportamentos, suas atitudes e resultados. Esta ação tende a motivar os colaboradores a continuarem engajados em prol dos objetivos da empresa; e já quando o Feedback é Negativo a equipe ou o colaborador tendem a mostrar resultados abaixo do esperado, seja em suas atitudes ou resultados (BENÍTEZ, 2001). É preciso ter muita sensibilidade para dar esse feedback ao colaborador, para não gerar conflitos maiores e desgaste desnecessário entre os membros da equipe.

\section{Procedimentos Metodológicos}

A metodologia adotada neste artigo foi à revisão bibliográfica acerca da importância do clima organizacional para organizações, que têm por objetivo reunir trabalhos de outros autores, com a intenção de conhecer melhor a temática e suas pesquisas para um melhor aprofundamento do estudo e suas inovações no decorrer do tempo e aplicabilidade no setor público como meio de melhorar a forma de abordar o conteúdo e suas formas e servir de referencial para futuros estudos.

Para Caldas (2000, p. 15) a pesquisa bibliográfica representa a "coleta e armazenagem de dados de entrada para a revisão, processando-se mediante levantamento das publicações 
existentes sobre o assunto ou problema em estudo, seleção, leitura e fichamento das informações relevantes". Através da análise bibliográfica sobre livros e artigos publicanos na internet ela dá um suporte para poder confrontar e obter um número suficiente de informações sobre determinado tema há ser debatido com propriedade sem ocasionar nenhum desvio de opinião de um único material bibliográfico.

\section{Considerações Finais}

A gestão do clima organizacional contribui significativamente no comportamento das pessoas e que falta aos gestores, maior conhecimento sobre os colaboradores para que possam desempenhar melhor suas funções. Nesse sentido, visando minimizar possíveis tendências no setor público, esse trabalho abordou o endomarketing como ferramenta de motivação, pois, o conhecimento do perfil motivacional do colaborador possibilita o desenvolvimento de programas diferenciados voltados para a satisfação de seus colaboradores dentro das organizações. Dessa forma, há uma tendência ao favorecimento de um Clima e Comportamento Organizacional mais eficaz. Não se deve desvincular as metas do trabalhador das estratégias de motivação laboral levadas a cabo em uma determinada organização, pois se assim for, pode estar fadada ao insucesso.

A partir do momento em que existe um levantamento analítico do ambiente interno da empresa, torna-se possível enfrentar com maior assertividade, os principais focos das eventuais dificuldades ali existentes, melhorando o clima de trabalho e relacionamento das pessoas.

É fundamental o espírito de equipe, a comunicação aberta e a confiança entre todos os membros da equipe. O que se pode observar, também, é que a liderança tem um papel fundamental na criação de um ambiente de trabalho, onde as pessoas têm prazer em trabalhar, pois os líderes são responsáveis pela integração da sua equipe de trabalho e pelo reconhecimento e valorização das pessoas. Um clima agradável no trabalho é vantajoso para ambas as partes, funcionários e empresa, e o resultado é menos estresse, mais prazer em fazer parte da empresa, mais envolvimento com o trabalho e melhores desempenhos e resultados. 


\section{Referências}

ANDRADE, Murilo Martins. Endomarketing inteligente: a empresa pensada de dentro para fora. Rev. adm. contemp., Curitiba, v. 15, n. 3, p. 560, June 2011.

BENÍTEZ, Zaira Ramos. Os gerentes atuando como facilitadores da comunicação interpessoal para incrementar a criação do conhecimento organizacional . 2001. 251f. Dissertação (Mestrado em Administração) - Universidade Federal de Santa Catarina. Florianópolis. Disponível em: <http://teses.eps.ufsc.br/Resumo.asp?1799>. Acesso em: 07 junho 2018.

BERGAMINI, Cecília Whitaker; CODA, Roberto. Psicodinâmica da Vida Organizacional: Motivação e Liderança. $2^{\text {a }}$ ed. São Paulo: Atlas, 1997.

CALDAS, Maria Aparecida Esteves. Estudos de revisão de literatura: fundamentação e estratégia metodológica. São Paulo: Hucitec, 2000.

CHIAVENATO, Idalberto. Gestão de Pessoas: O Novo Papel dos Recursos Humanos nas Organizações. 9a Tiragem. Rio de Janeiro: Campus, 1999.

DECRETO $\mathbf{n}^{\mathbf{0}}$ 5.707 de 23 de fevereiro de 2006. Dispõem sobre as políticas e diretrizes para o desenvolvimento de pessoal da administração pública direta, autárquica e fundacional e regulamenta dispositivos da lei $\mathbf{8 . 1 1 2}$ de 11 de dezembro de 1990 .

GODINHO, M.; MENDES, R.; BARREIROS, J. Informação de Retorno e Aprendizagem. Horizonte. Lisboa: Livros Horizonte, v. 11, n. 66, mar./abr. 1995.

KAHALE, Flávia. Pesquisando a Motivação: A Pesquisa de Clima organizacional. Instituto MVC, disponível em http://www.institutomvc.com.br/clima.htm Acessado em: 12 de maio de 2018.

MELLO, Álvaro. O modelo de gestão por competências: Uma abordagem crítica. São Paulo: EAESP/FGV, 2003. 51 p.

OLIVEIRA, Marco A. A face oculta da empresa: como decifrar e gerenciar a cultura corporativa. Rio de Janeiro: Senac Rio, 1995

ROBBINS, S. P. Comportamento organizacional. São Paulo: Prentice Hall, 2002,p.135.

Como citar este artigo (Formato ABNT):

SILVA, Teilma Maria da. VIANA, Cíntia Milena Cid; FEITOSA, Leandro da Cruz. O Impacto da Gestão do Clima Organizacional no Comportamento das Pessoas do Setor Publico. Id on Line Rev.Mult. Psic., 2018, vol.12, n.42, p. 213-224. ISSN: 1981-1179.

Recebido: 23/08/2018;

Aceito: $28 / 08 / 2018$ 